\title{
Modal identification of Bridge 44 of the Carajás Railroad and numerical modeling using the finite element method
}

\author{
Identificação modal da Ponte 44 da Estrada de Ferro \\ Carajás e modelagem numérica via método dos \\ elementos finitos
}

M. S. SILVA a $\frac{\text { marcelass 1505@yahoo.com.br }}{\text { https://orcid.org/0000-0002-6834-9212 }}$

F. A. NEVES a

fassis@ufop.edu.br https://orcid.org/0000-0003-2735-1751

\begin{abstract}
Regular use and the effects of time can affect the behavior of a structure. Over time, problems such as the occurrence of small fissures, oxidation of steel elements, and excessive displacements at some points may arise in a structure. In this context, the monitoring of structures through experimental tests has gained more importance, because it allows for the identification of the dynamic characteristics (natural frequencies, mode shapes, and damping rate) of structures. The dynamic characteristics can be obtained through forced vibration tests, which are based on measuring the response of a structure subjected to an excitation of known magnitude, or through tests in which only the structural response is measured, such as free vibration and ambient vibration tests. The present study aims to identify the modal parameters of bridge 44 of the Carajás Railroad, using experimental data obtained on site by monitoring the vibration caused by a group of people jumping, and it compares them with the results obtained through numerical modeling performed using the finite element method, developed in CSiBridge. The modal parameters were obtained using the commercial software ARTeMIS Modal, and stochastic subspace identification was used for modal identification.
\end{abstract}

Keywords: bridge, operational modal analysis, stochastic subspace identification, numerical modeling.

\section{Resumo}

A utilização e os efeitos do tempo podem afetar o comportamento de uma estrutura. Problemas como pequenas fissuras, oxidação de elementos de aço e deslocamentos excessivos em alguns pontos poderão surgir. Nesse contexto, o monitoramento de estruturas por meio de ensaios experimentais ganhou mais importância, por permitir a identificação das suas características dinâmicas (frequências naturais, modos de vibração e taxa de amortecimento). Estas podem ser obtidas a partir de ensaios de vibração forçada, que se baseiam na medição da resposta da estrutura sujeita a uma excitação induzida com magnitude conhecida, ou a partir de ensaios em que apenas a resposta da estrutura é medida, como os ensaios de vibração livre e vibração ambiente. O presente trabalho tem como objetivo identificar os parâmetros modais da Ponte 44 da Estrada de Ferro Carajás, com base em dados experimentais obtidos "in loco" durante o monitoramento com vibração de caráter aleatório e compará-los com os resultados obtidos por meio da modelagem numérica via método dos elementos finitos, desenvolvido no CSiBridge. A obtenção dos parâmetros modais foi realizada no software comercial ARTeMIS Modal e o método de identificação modal utilizado foi de identificação estocástica em subespaço (SSI-UPC).

Palavras-chave: ponte, análise modal operacional, identificação estocástica de subespaço, modelagem numérica.

Federal University of Ouro Preto, Department of Civil Engineering, Graduate Program in Civil Engineering, Ouro Preto, MG, Brazil.

Received: 28 May 2016 • Accepted: 12 Jun 2019 • Available Online: 23 Jan 2020

Ther is an open-access article distributed under the terms of the Creative Commons Attribution License 


\section{Introduction}

The safety conditions of large civil engineering structures are usually analyzed from the initial design and construction phases to the eventual end phases to check whether they need to be rehabilitated or reinforced. These analyses can be conducted using numerical models, in general with finite element formulations, for static and dynamic analysis. Simulation of structural behavior by means of numerical models is important; however, such models do not always represent the real behavior of the structure, because modeling a real structure is complex, and thus some simplifications need to be made.

Adopting techniques for identifying the modal parameters of a structure (natural frequencies, mode shapes, and damping rate) based on the performance of dynamic tests may be a suitable approach to obtain more effective responses because they allow for the analysis of correlations between identified and calculated parameters. These results can contribute significantly to the updating and experimental validation of developed numerical models and the consequent evaluation of the effective load capacity of structures.

Modal parameters of a structure can be identified through the following two approaches: experimental modal analysis or operational modal analysis (OMA). In the first case (also called input-output analysis), the modal parameters are estimated from the relationship between the input data (applied excitation) and output (dynamic response). In OMA (also called output-only analysis), the modal parameters are estimated only with the output data.

OMA has been shown to be efficient and has been used mainly for the validation and refinement of finite element models, structural modification, damage detection, and analysis of complex structures. In this context, the modal parameters of bridge 44, were identified through data acquisition using OMA. This study is a joint project between Fapemig Vale Federal University of Ouro Preto and Federal University of Pará. The main objectives of the study are as follows:

- To estimate the dynamic properties of bridge 44 of the Carajás Railroad through OMA, using the commercial software ARTeMIS Modal, the experimental data on site were obtained based on vibrations in the structure caused by random characteristics;

- To develop a numerical model calibrated with data obtained during the monitoring of bridge 44 .

During the channel post-processing phase, the following problems were identified:

i. There was supersampling of the data obtained: The highest numerical frequency obtained was $25 \mathrm{~Hz}$; however, during the monitoring phase, the sampling frequency of the test was $500 \mathrm{~Hz}$ and the maximum limit of the reproduced signal was $250 \mathrm{~Hz}$ (the Nyquist frequency). As the energy applied by people jumping on the bridge was not sufficient to excite the main bending modes, the excess data may contain spurious information.

ii. Some accelerometers did not work and had to be discarded.
To improve the results, several analyses were performed; these included signal filtering during the post-processing phase and changing the number of projection channels and order of the model.

The data used in this study were provided by the Nucleus of Instrumentation and Applied Computing to Engineering (NICAE), an associate group of the Federal University of Pará that has performed experimental vibrational analyses of the concrete and steel bridges of the Carajás Railroad. The authors did not participate in the monitoring, so all information on the tests was passed on by the group.

Currently, the structures are in high demand owing to their performance and useful life. Consequently, the engineering branch known as structural health monitoring (SHM) has attracted more attention and gained visibility. SHM facilitates the detection of unusual structural behavior that indicates structure malfunction, to minimize repair and maintenance costs and to provide a higher level of safety to users. According to Farrar et al. [1], this process of damage detection using SHM involves the acquisition, validation, and analysis of data. The following are some of the works developed in this area that point to new approaches.

Lobato et al. [2] presented the results of an experimental and computational modal analysis of a metallic railroad bridge spanning the Mearim River (Maranhão). The objective of the analysis was to verify the numerical models used in the structural analysis of a metallic span, to facilitate greater precision in the computational simulations of the static and dynamic behaviors of a structure

Sampaio et al. [3] identified the modal parameters of four railroad bridges located in the north of Brazil. The analyzed bridges were constructed of reinforced concrete and had medium and short extensions, varying between 9.50 and 25.00 $\mathrm{m}$. Temporal series were obtained using different excitation sources: free vibration after a train passage, vibrations due to people jumping, and vibrations arising from a "drop weight" system under ambient conditions. The identification of the modal parameters was performed using the commercial software ARTeMIS Modal (SVS 2011). Finally, the experimental results were compared with those obtained with the computational model.

Costa et al. [4] calibrated a numerical model of a railroad bridge, using modal parameters estimated through an ambient vibration test.

Suleyman [5] developed an algorithm to automate the dynamic identification of structures using the stochastic subspace identification (SSI) method. Afterward, he used this algorithm to determine the modal parameters of the São João railroad bridge.

\section{Stochastic Subspace Identification (SSI)}

The SSI method is based on the analysis of the experimental data of the response temporal series to perform the model adjustment; thus, it is classified as a time-domain modal identification method. Problems of this nature can be solved through two distinct methods: SSI-COV and SSI-DATA. The first method is based on an adjustment of the correlation 
functions of the system response, while the second entails direct adjustment of the system response series (Rodrigues, [6]).

\subsection{Description of the method}

For identifying stochastic systems, in which the input data have unknown (random) magnitude, it is assumed that the excitation force has characteristics of a white-noise signal with zero mean. This condition needs to be met to ensure that the formulations presented below are valid.

According to van Overschee et al. [7], SSI algorithms calculate state space models from the output data. Figure 1 shows a linear, time-invariant stochastic (output-only) system with output data $y_{k}$ and states $x_{k}$, described by matrices $A$ and $C$. The random (unknown) input and output data are represented, respectively, by $w_{k}$ and $v_{k}$. The symbol $\Delta$ represents a delay.

Following the approach used by Subspace Identification for Linear Systems: Theory, implementation, applications van Overschee et al. [7] and Peeters [8], the purely stochastic state space model can be described by the following set of equations:

$\boldsymbol{x}_{k+1}=\boldsymbol{A} \boldsymbol{x}_{k}+\boldsymbol{w}_{k}$

$\boldsymbol{y}_{k}=\boldsymbol{C} \boldsymbol{x}_{k}+\boldsymbol{v}_{k}$

where $y_{k}$ is the vector that allocates measurements at time instant $k$ of the l output of the process, $x_{k} \in \mathbb{R}^{n}$ is the state vector of the process at the discrete time instant $k$ and contains the numerical values of $n$ states, and $v_{k} \in \mathbb{R}^{1}$ and $w_{k} \in \mathbb{R}^{n}$ are unmeasurable vector signals (i.e., process noise and sensor inaccuracies). It is assumed that they are zero mean, stationary, white vector sequences.

The matrix $A \in \mathbb{R}^{n \times n}$ is called the $n$ order system matrix; it describes the dynamics of the system. $C \in \mathbb{R}^{1 \times n}$ is the output data matrix; it describes how the internal state is transferred to the external state in the measures $y_{k} \in \mathbb{R}^{1}$.

Assuming that the stochastic system is stationary, we have the following set of equations:

$E\left[\boldsymbol{x}_{k}\right]=\mathbf{0}$

$E\left[\boldsymbol{x}_{k}\left(\boldsymbol{x}_{k}\right)^{T}\right]=\boldsymbol{\Sigma}$ where $\Sigma$ is the state covariance matrix (also called simply the covariance matrix), independent of $k$ time.

After algebraic manipulations, we arrive at:

$\boldsymbol{\Sigma}=\boldsymbol{A} \boldsymbol{\Sigma} \boldsymbol{A}^{T}+\boldsymbol{Q}$

$\boldsymbol{\Lambda}_{i}=\boldsymbol{C} \boldsymbol{\Sigma} \boldsymbol{C}^{T}+\boldsymbol{R}$

$\boldsymbol{G}=\boldsymbol{A} \boldsymbol{\Sigma} \boldsymbol{C}^{T}+\boldsymbol{S}$

These equations are formed by the system matrices ( $A$ and C), noise covariance matrices $\left(Q \in \mathbb{R}^{n \times n}, R \in \mathbb{R}^{1 \times 1}\right.$ and $\left.S \in \mathbb{R}^{n \times 1}\right)$, response covariance matrix $\left(\Lambda_{\mathrm{i}}\right)$, and covariance matrix between the state vectors at instant $k+1$ and the response at instant $k(G)$. Through this set of equations, it is possible to establish the equality:

$\Lambda_{i}=\boldsymbol{C A}{ }^{i-1} \boldsymbol{G}$

There are two distinct methods to determine the system matrices (A and $\mathbf{C}$ ), which were previously defined by Equations (1) - (4): the SSI-COV and SSI-DATA methods.

In the present work, only SSI-DATA was used. Some theoretical foundation about the method and its formulation are presented below.

\subsection{SSI-DATA}

The SSI method is used to identify the system matrices A and $C$ from the system output measurements $y_{k}$. We follow the approach used by van Overschee et al. [7] and Weng et al. [9], using the following steps for calculating the system matrices:

1. By using the (measured) output data $y_{k}$, the Hankel matrix $(\mathrm{Y})$ is constructed by:

$\boldsymbol{Y}=\left[\begin{array}{cccc}y_{0} & y_{1} & \cdots & y_{N-1} \\ y_{1} & y_{2} & \cdots & y_{N} \\ \cdots & \cdots & \cdots & \cdots \\ y_{i-1} & y_{i} & \cdots & y_{i+N-2} \\ \hline y_{i} & y_{i+1} & \cdots & y_{i+N-1} \\ y_{i+1} & y_{i+2} & \cdots & y_{i+N} \\ \cdots & \cdots & \cdots & \cdots \\ y_{2 i-1} & y_{2 i} & \cdots & y_{2 i+N-2}\end{array}\right]=\left[\begin{array}{l}\boldsymbol{Y}_{p} \\ \boldsymbol{Y}_{f}\end{array}\right]$

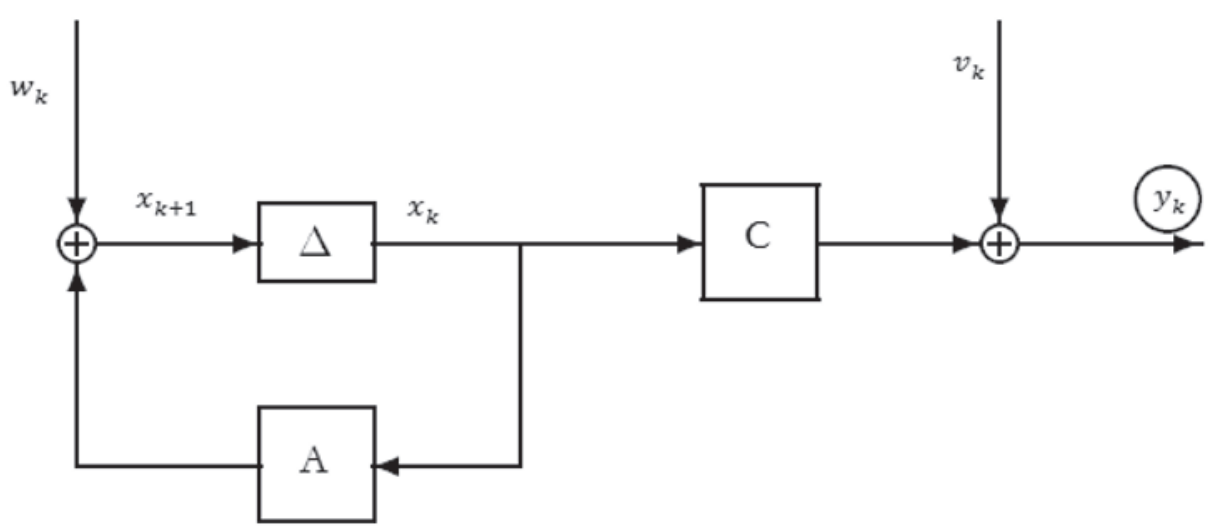

\section{Figure 1}

Representation of a purely stochastic system (Adaptado de Van Overschee et al. [7]) 
Here $i$ is a user-defined index that corresponding to the number of row blocks; this must be greater than the $\mathrm{n}$ order of the system. Once each line block has I lines (number of output channels), the $\mathrm{Y}$ matrix must contain 2li lines. $\mathrm{N}$ corresponds to the number of columns in the Hankel matrix. To ensure that all time samples from the output vector fill this array, the value of $\mathrm{N}$ must be equal to $\mathrm{s}-2 \mathrm{i}+1$.

2. We then calculate the orthogonal projection $(P)$ of the "future" response series $Y_{f}$ in the space of the "past" response series $Y_{p}$ according to:

$\boldsymbol{P}=\boldsymbol{Y}_{f} / \boldsymbol{Y}_{p}=\boldsymbol{Y}_{f} \boldsymbol{Y}_{p}^{T}\left(\boldsymbol{Y}_{p} \boldsymbol{Y}_{p}^{T}\right)^{\dagger} \boldsymbol{Y}_{p}$

where $\bullet^{\dagger}$ is the pseudo-inverse matrix (Moore-Penrose matrix) of $\bullet$. The products $\boldsymbol{Y}_{f} \boldsymbol{Y}_{p}^{T}$ and $\boldsymbol{Y}_{p} \boldsymbol{Y}_{p}^{T}$ are Toeplitz matrices of the response correlation functions. However, Equation (6) is only the definition of the orthogonal projection of spaces $\mathrm{P}$, because it is not possible to ascertain how this projection is calculated in the SSI-DATA method (Rodrigues, [6]). Therefore, the orthogonal projection for the SSI-DATA method is calculated by means of $Q R$ decomposition.

3. Singular value decomposition $\left(S V^{1}\right)$ of the orthogonal projection $(P)$ is then performed. In this case, it is used to decompose the orthogonal projection of Hankel's matrix:

$\boldsymbol{P}=\boldsymbol{U} \boldsymbol{S} \boldsymbol{V}^{T}$

The order $\mathrm{n}$ of the system is determined through the inspection of the rank of matrix $S$ (number of nonzero singular values) and partitioning the SVD to obtain $\mathrm{U}_{1}$ and $\mathrm{S}_{1}$ :

$\boldsymbol{U} \boldsymbol{S} V^{T}=\left(\begin{array}{ll}\boldsymbol{U}_{1} & \boldsymbol{U}_{2}\end{array}\right)\left(\begin{array}{cc}\boldsymbol{S}_{1} & \mathbf{0} \\ \mathbf{0} & \mathbf{0}\end{array}\right)\left(\begin{array}{l}\boldsymbol{V}_{1}^{T} \\ \boldsymbol{V}_{2}^{T}\end{array}\right)$

5. The extended observability matrix $\left(\Gamma_{\mathrm{i}}\right)$ can be calculated through:

$\Gamma_{i}=\left[\begin{array}{c}C \\ C A \\ C A^{2} \\ \cdots \\ C A^{I-1}\end{array}\right]$

6. The state matrices $A$ of the system are calculated through $\Gamma_{\mathrm{i}}$ according to:

$\boldsymbol{A}=\underline{\Gamma}_{i}^{\dagger} \overline{\boldsymbol{\Gamma}}_{i}$

where $\underline{\Gamma}_{i} \in \mathbb{R}^{l(i-1) \times n}$ is $\Gamma_{\mathrm{i}}$ without the last I lines (number of channels) and $\overline{\boldsymbol{\Gamma}}_{i} \in \mathbb{R}^{l(i-1) \times n}$ is $\Gamma_{i}$ without the first I lines.

7. The matrix $C$ can be determined from the first I lines of $\Gamma_{i}$ as shown in Equation (9).

After determination of the state matrices ( $A$ and $C$ ) by means of the SSI-DATA method, the modal parameters (natural frequencies $\omega_{i}$, mode shapes $\phi_{i}$, and damping rates $\xi_{i}$ ) of the dynamic system are determined. This calculation entails extracting the eigenvalues $\mu_{i}$ and eigenvectors $\psi_{i}$ from A, but as the calculation of these eigenvalues $\mu_{i}$ takes a discrete time (with steps of time $\Delta_{\mathrm{t}}$ ), it is necessary to transform to continuous time.
8. The eigenvalues of $A$ in continuous time $\left(\lambda_{i}\right)$ are calculated according to:

$\lambda_{i}=\frac{\ln \left(\mu_{i}\right)}{\Delta_{t}}$

in which the eigenvalues $\left(\mu_{i}\right.$ or $\left.\lambda_{i}\right)$ of $A$, also called poles, are complex numbers that appear in conjugate pairs.

The natural frequencies are the modules (amplitudes of vectors in the imaginary-real plane) of the poles of $A$ :

$\omega_{i}=\left|\lambda_{i}\right|=\sqrt{\operatorname{Im}\left(\lambda_{i}\right)^{2}+\operatorname{Re}\left(\lambda_{i}\right)^{2}}(\mathrm{rad} / \mathrm{s})$,

$f_{i}=\frac{\omega_{i}}{2 \pi}(\mathrm{Hz})$,

where $\operatorname{Im}(\boldsymbol{\square})$ represents the imaginary part and $\operatorname{Re}(\boldsymbol{\Xi})$ the real part of $\mathbf{m}$. Therefore, the damping rates are calculated as:

$\xi_{i}=\frac{-\operatorname{Re}\left(\lambda_{i}\right)}{\left|\lambda_{i}\right|} \cdot 100(\%)$

The mode shapes $\phi_{\mathrm{i}}$ are obtained by multiplying the matrix $\mathrm{C}$ with the eigenvectors $\left(\psi_{i}\right)$ of $A$ :

$\phi_{i}=\boldsymbol{C} \psi_{i}$

In this way, the modal parameters of the system are calculated for the various modes identified. The number of modes obtained is equal to the number of eigenvalues of $A$ that have conjugate pairs and a positive imaginary component. For this reason, because this matrix is of order $\mathrm{n}$ (order of the model), it is concluded that, at most, $n / 2$ modes can be identified.

\subsection{Stabilization diagram}

Up to the present moment, no analysis has been carried out to determine the order $\mathrm{n}$ that the state space model must have to identify the dynamic parameters of the system efficiently. This analysis is one of the most important aspects in parametric methods of modal identification because it directly affects the quality and authenticity of the identified modes.

The order $n$ of the model must be at least twice as high as the number of modes (or poles) expected, because they appear in conjugated complex pairs (with each pair corresponding to a calculated mode). Initially, it is not possible to measure the number of physical modes only through the experimental data, because this is one of the results of the modal identification analysis. Therefore, to assist in the definition of the appropriate order, there are some procedures through which models of different orders are estimated and compared based on quality criteria, such as the Akaike information criterion, Akaike's final prediction error, or the minimum descriptive length of Rissanen (Peeters [8]; Andersen et. al 1997 [10]; Ljung [11]). These criteria, which are actually measures of the error of the parametric models, demonstrate that, as the order of the model increases, the error tends to decrease to a certain order in which it becomes asymptotic; that is, the error does not considerably

SVD is a factorization tool used for real matrices or rectangular complex matrices. 
increase with the order of the models. Therefore, the order for which the beginning of the asymptotic variation of the error occurs is indicated to represent the system.

Although it is possible to use the above-mentioned error criteria to assist in choosing the order of the model to be identified, in practice its use is not always easy. In addition, it is known that modal identification aims to estimate the modal characteristics of the structural system and not of its own model of this system, expressed through the matrices of state $A$ and $C$. Thus, for the analysis of modal identification with parametric models (in the time domain), a new tool, called a stabilization diagram, has emerged that is more practical to use than those previously mentioned.

According to Rodrigues [6], the stabilization diagram gathers the results of the identification for several orders of models of the same system. In this diagram, the abscissa axis represents the frequencies of the modes and the ordinate axis represents the order of the model used for identification. To construct the diagram, the poles of a model of a particular order are compared to the poles of a model of a close order. If the difference between these poles does not exceed certain predetermined limits in terms of frequency, damping rate, and modal components, the pole is stable; otherwise, the pole is unstable. It is verified that the system's own modes, that is, those that exhibit higher amplitudes of vibration and consequently more prone to excitation, stabilize for models of lower order. In contrast, the slightly excited modes, those that exhibit amplitudes almost of the same order as the noise, only stabilize for models of higher orders. Therefore, it is convenient to consider high-order models to enable identification of these modes, which are barely evident in the experimentally measured responses.

\subsection{Projection channels}

According to Herlufsen et al. [12], when many sensors take

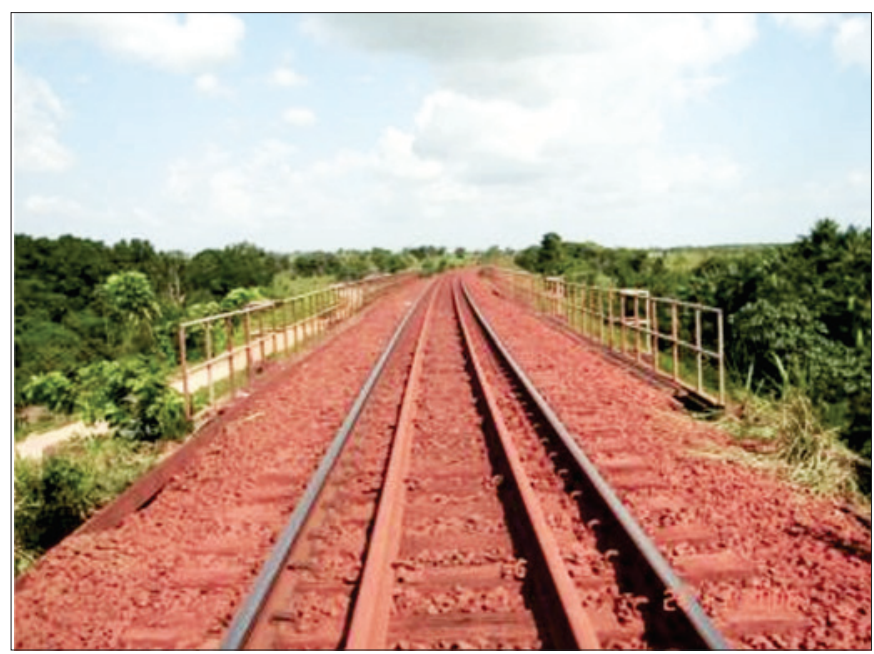

Figure 2

(a) View of the bridge deck over the Martírio River (b) Bridge overview (Rodrigues Júnior et al. [14]) measurements simultaneously, many spurious modes can be estimated, compared with the number of physical modes of the system during the adjustment of the parametric model. This is because many channels have the same physical information but different random errors. One way of reducing the number of spurious modes is to reduce the number of channels during the data acquisition process, without losing information of the physical modes and the representativeness of the system.

Projection channels are used to reduce the amount of redundant information, which results in the estimated models stabilizing faster. The selection of projection channels starts with the selection of the channel that correlates the most with the others; in the case of sets of arrangements, the reference channels (those common to all the arrangements) are used as initial projection channels (Sampaio, [3]). Failure to do so may cause some modes to be detected as noise (Nguyen, [13]). A description of the method can be found in Herlufsen et al. [12].

\subsection{Modal complexity}

The graphical representation in the complex plane (Argand plane) for a given identified mode is given by the vector representation of the components of this mode. This means that the higher the values of the imaginary components (represented in the plane outside the horizontal axis, the real axis), the greater is the tendency for a non-physical mode to occur. In Section 4, referring to the results, two plots are shown, one referring to a real mode and another referring to a complex mode.

\section{Case study: Bridge 44 over the Martírio River}

The object of this study is bridge 44 of the Carajás Railroad, shown in Figure 2. It is located at km 615+500, in the municipality of São Luís, over the Martírio River.

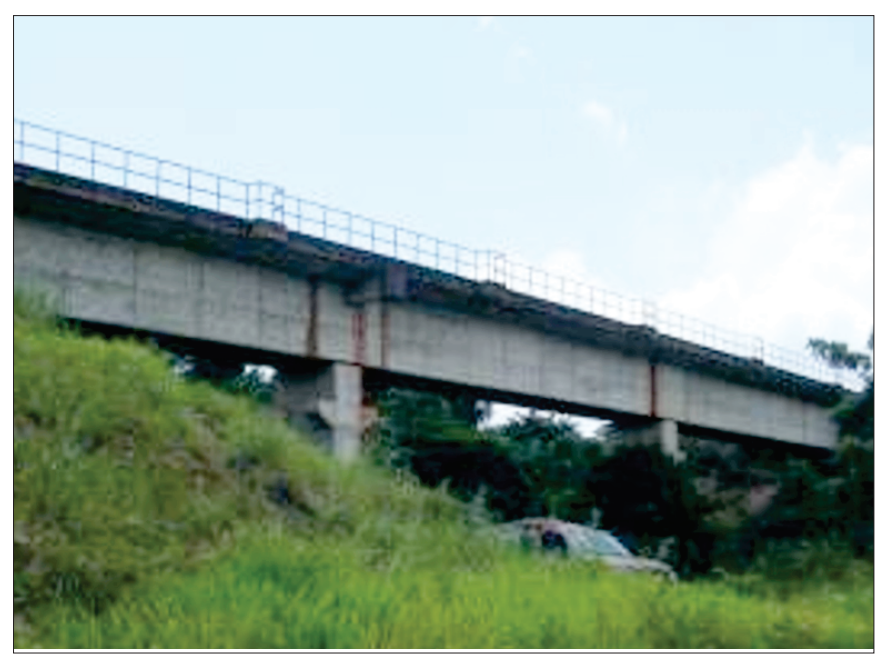




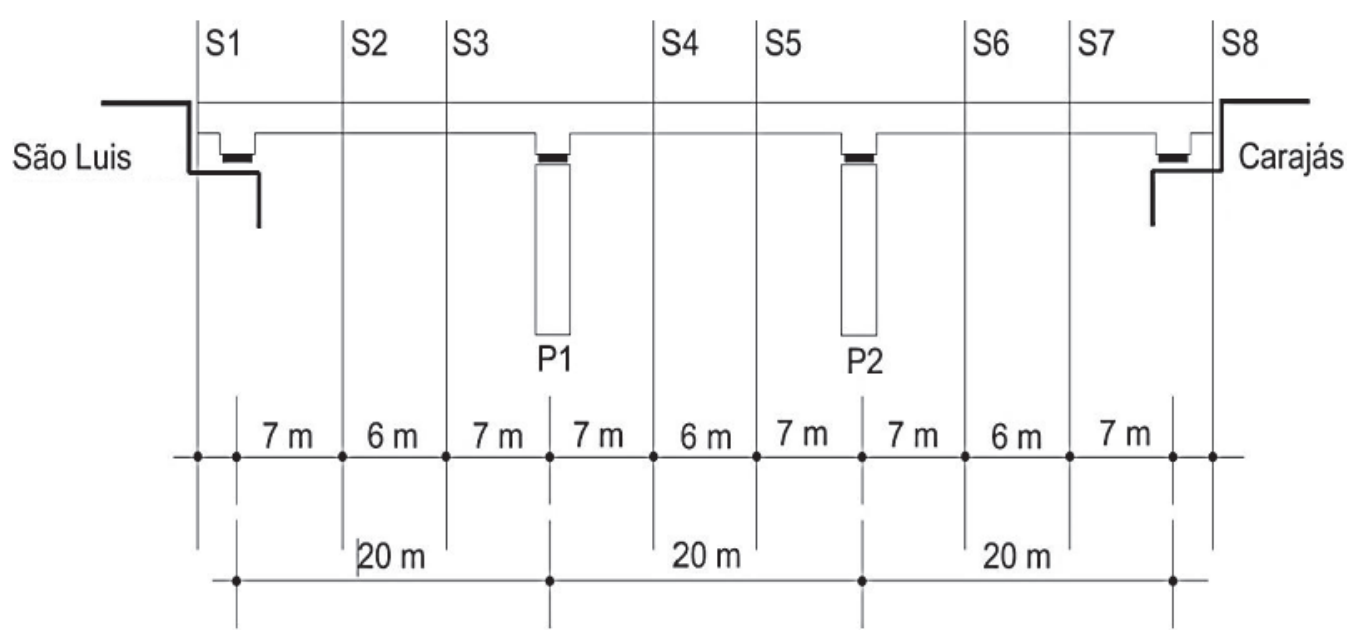

\section{Figure 3}

Sections adopted in the test

This bridge, constructed of reinforced concrete, has a total extension of $60.00 \mathrm{~m}$, consisting of three spans of $20.00 \mathrm{~m}$ each. The superstructure is composed of two main girders (stringers) and transversal beams distributed every $5.00 \mathrm{~m}$ in the span of the bridge deck. The stringers and the bridge deck form a continuous structural system simply supported on a neoprene elastomeric bearing pads. The bridge deck has a total width of $5.85 \mathrm{~m}$.

The mesostructure is formed by isolated columns with a rectan- gular cross section of $1.20 \times 2.80 \mathrm{~m}$ and a height of $10.00 \mathrm{~m}$, inserted in foundation blocks of reinforced concrete on a drilled pier. The drilled piers are $1.40 \mathrm{~m}$ in diameter, with an enlarged base of $2.90 \mathrm{~m}$, which constitute the infrastructure of the bridge.

\section{Monitoring program}

The phase that preceded the on-site vibration test was the

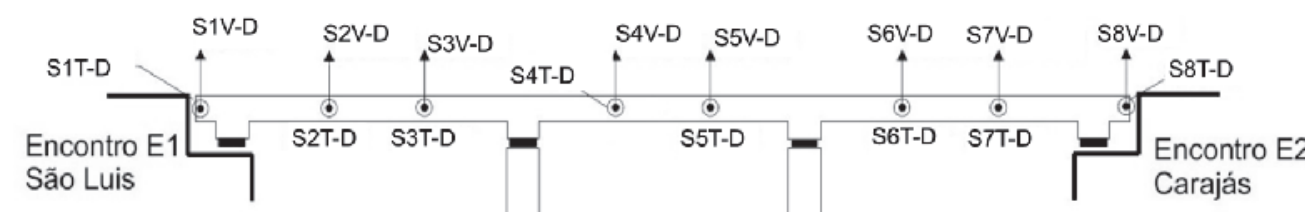

lado direito

(a)

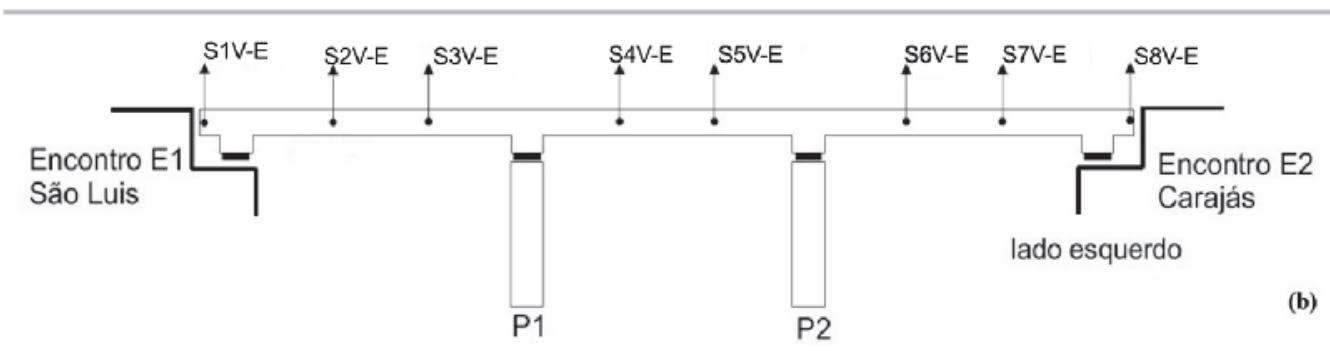

Figure 4

Arrangements of accelerometers on the right side of the superstructure (b) Arrangement of accelerometers on the left side of the superstructure. Where Sn represents the section to which the accelerometer is positioned, $\mathrm{n}$ corresponds to the section number, $\mathrm{V}$ is the vertical direction, $\mathrm{T}$ is the transverse direction, $\mathrm{D}$ is the right side, and $\mathrm{E}$ is the left side 
development of a numerical model using the finite element method in the commercial software CSiBridge [15]. For that, the geometric and mechanical properties of the structural elements obtained from the original project were used. By idealizing all the acting actions, it was possible to simulate the behavior of the structure and thus identify the approximate value of the natural frequencies and the mode shapes.

For measuring the bridge deck vibrations, 24 low-frequency piezoelectric accelerometers (Wilcoxon ${ }^{\circledR}$ model $793 \mathrm{~L}$ ), with a frequency response between 0.2 and $2300 \mathrm{~Hz}$ and a nominal sensitivity of $500 \mathrm{mV} / \mathrm{g}$, were arranged in selected locations (sections) to measure the acceleration in the vertical and transverse directions. The sampling frequency used was $500 \mathrm{~Hz}$.

The accelerometers were positioned at $1 / 3$ and $2 / 3$ of the span, in agreement with the ABNT NBR [15] 15307:2006 (Non-destructive tests: Dynamic loads tests on large structures - Procedure) and by considering the modal configurations obtained from the numerical model. The structure was divided into eight sections, according to Figure 3 , and the distribution of the accelerometers along the bridge deck is shown in Figures 4(a) and 4(b).

During data acquisition, the following were performed: positioning and fixation of the accelerometers according to the sections, connection of the accelerometers to the data acquisition system (LYNX® ADS-2000) through cables, and configuration of the test parameters (sampling frequency and duration of the test) in the commercial software AqDados 7 [17a]. The structure was subjected to three types of excitation: (i) ambient vibration (under the action of wind); (ii) excitation resulting from the passage of loaded and unloaded trains, and (iii) vibrations with random characteristics introduced by people jumping on each of the spans. The temporal series related to the passage of the loaded train was used only to measure the acceleration of the structure, since previous studies demonstrated that the use of this series does not generate reliable results of the dynamic characteristics of the bridge. This is because the mass of a loaded train can influence the dynamic characteristics of the structure during the tests [2].
When this temporal series is used, it is difficult to stabilize the dynamic characteristics for creating the stabilization diagrams [2]. The temporal series of the wind was insufficient for exciting the structure. Therefore, the signals used to perform OMA, through the ARTeMIS Modal commercial software [18], were those of vibrations resulting from people jumping on each span of the structure in a nonconcomitant manner. The test lasted $3 \mathrm{~min}$ and $39 \mathrm{~s}$ and a sampling frequency of 500 $\mathrm{Hz}$ was used. Figure 5 shows the temporal series obtained for the accelerometers S2V-D and S2T-D during monitoring. These temporal series presented in Figure 5 were not postprocessed; it was verified that all the signals exhibited spurious signals in the initial and final instants of monitoring. To improve the quality of the signals acquired, the AqDAnalysis 7 [17b] program was used to perform post-processing; all the time series were numerically filtered by a high-pass filter of $0.2 \mathrm{~Hz}$ and order 5 . In this type of filter, a cutoff frequency is defined; frequencies up to this value suffer infinite attenuation, whereas higher frequencies suffer null attenuation. The cutoff frequency of $0.20 \mathrm{~Hz}$ was chosen to increase the accuracy of the test, because the frequency response of the accelerometer used was 0.2 to $2300 \mathrm{~Hz}$. Another signal post-processing technique employed was the cut in the initial and final stretches of the monitoring, so that only the stretches that had energy concentrated were used. The duration after the cut was $1 \mathrm{~min}$ and $35 \mathrm{~s}$. Figure 6 shows the temporal series of the same accelerometers shown in Figure 5 after these interventions.

From the analysis of the temporal series presented in Figures 5 and 6 , it was verified that the use of the high-pass filter and the cut in the duration of the monitoring had a positive influence on the signals because they eliminated spurious frequencies lower than $0.2 \mathrm{~Hz}$ and considered only the stretches in which there was excitement. Even after the interventions, six channels (S1V-E, S2V-E, S3V-D, S4V-E, S8V-E, and S8TD) did not show improvement and hence were discarded.

From the collected and post-processed signals, the modal parameters were identified using ARTeMIS Modal. For this, two tests were performed:

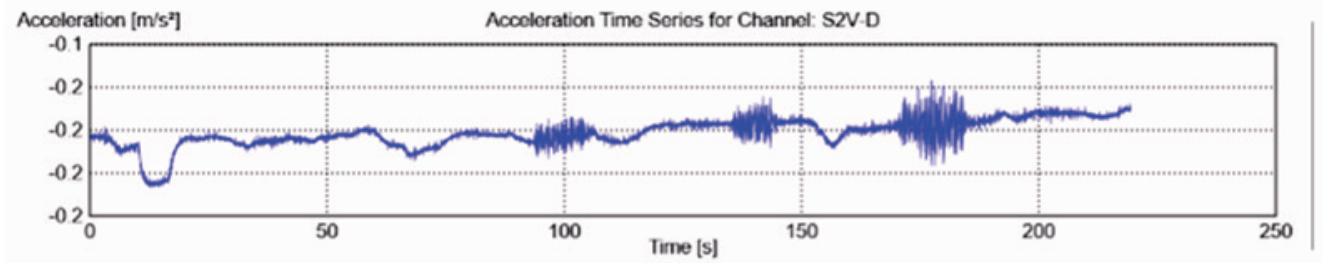

Statistics

Maximum $=-0.159\left[\mathrm{~m} / \mathrm{s}^{2}\right]$ Minimum $=-0.206[\mathrm{~m} / \mathrm{s}$ RMS $=0.181\left[\mathrm{~m} / \mathrm{s}^{2}\right]$ Median $=-0.182\left[\mathrm{~m} / \mathrm{s}^{\mathrm{2}}\right]$ Mean $=-0.181[\mathrm{~m} / \mathrm{s}]$ Sariance $\left.=0\left[\mathrm{~m} / \mathrm{s}^{2}\right)\right]$ Kurtosis $=5.801$

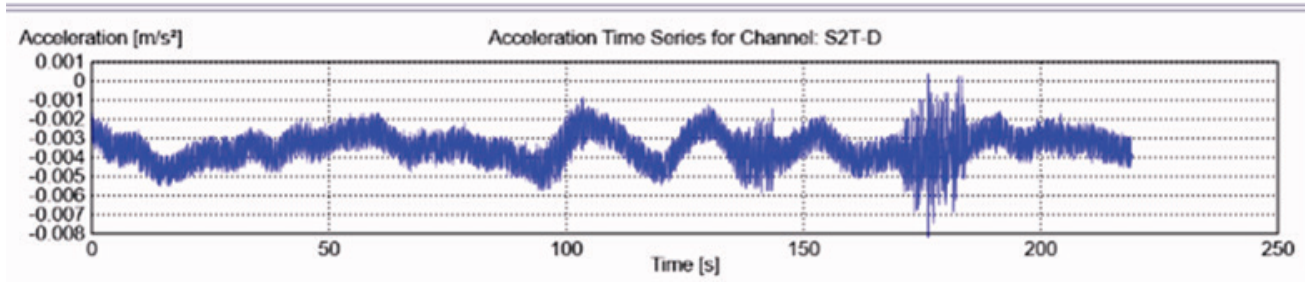

\section{Figure 5}

Temporal series of the accelerometers S2V-D, S2T-D 


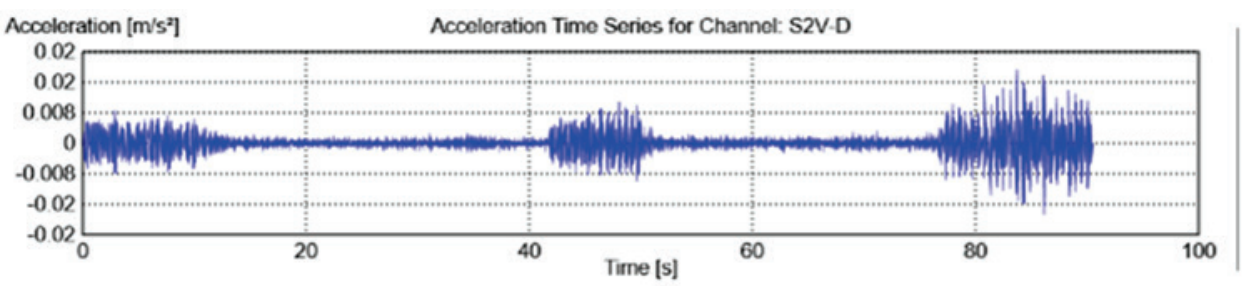

Statistics

Maximum $=0.018\left[\mathrm{~m} / \mathrm{s}^{\mathrm{s}}\right]$

Minimum $=-0.017\left[\mathrm{~m} / \mathrm{s}^{2}\right]$

RMS $=0.002\left[\mathrm{~m} / \mathrm{s}^{\mathrm{s}}\right]$

Median $=0\left[\mathrm{~m} / \mathrm{s}^{2}\right]$

Mean $=0\left[\mathrm{~m} / \mathrm{s}^{\circ}\right]$

Variance $=0\left[\mathrm{~m} / \mathrm{s}^{2}\right]^{3}$

Skewness $=0.055$
Kurtosis $=15.526$

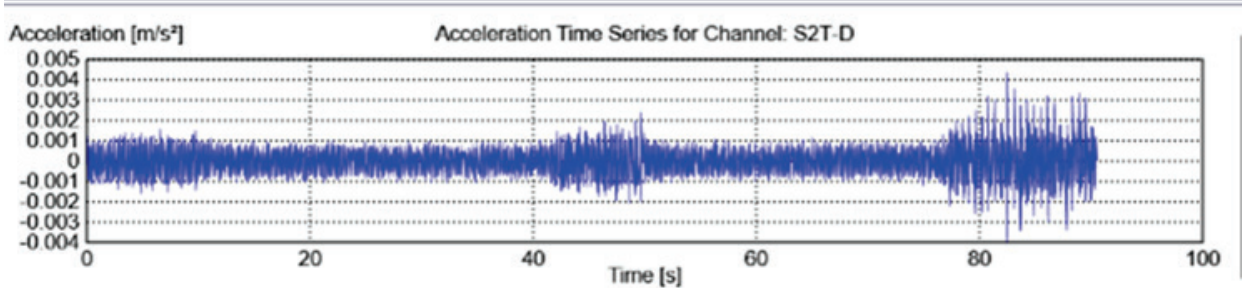

Statistics

Maximum $=0.004\left[\mathrm{~m} / \mathrm{s}^{\mathrm{s}}\right]$

Minimum $=-0.004\left[\mathrm{~m} / \mathrm{s}^{\mathrm{s}}\right]$

$R M S=0\left[\mathrm{~m} / \mathrm{s}^{2}\right]$

Median $=0\left[\mathrm{~m} / \mathrm{s}^{\mathrm{a}}\right]$

Mean $=0\left[\mathrm{~m} / \mathrm{s}^{\mathrm{s}}\right]$

Variance $=0\left[\mathrm{~m} / \mathrm{s}^{\mathrm{s}}\right]^{2}$

Skewness $=0.141$

Kurtosis $=9.879$

\section{Figure 6}

Temporal series of the S2V-D, S2T-D accelerometers after using the high-pass filter

i. Case I: 21 active channels were used, with the 6 channels mentioned above discarded.

ii. Case II: 14 active channels were used. Six accelerometers that did not work and all the transverse accelerometers were discarded.

For Case I, where 21 active channels were used, the results obtained were poorer than expected because the number of unstable modes was higher than the number of stable modes. This may have occurred because of stretches considered in the monitoring that did not contain any concentration of energy. To improve the results, the accelerometers that did not work and the transverse accelerometers were discarded, because the type of excitation applied in the structure was essentially vertical; thus, the transverse modes were not properly excited.
The results presented in Section 4 refer only to the analyses performed for Case II, as described above.

\section{Results}

Figure 7 illustrates the bridge under study, modeled in ARTeMIS Modal [18]. The vertical arrows indicate the accelerometers.

The dynamic properties of the bridge were obtained automatically by ARTeMIS Modal [18], using the SSI unweighted principal component (SSI-UPC method). The use of projection channels in the estimation of these parameters is very important owing to the number of channels present in the test. In this sense, some analyses were performed in which the number of projection channels and the order of the model were changed; however, before presenting them, it is necessary to describe some

\section{All channels of Test Setup: PULOMETRIA5_F}

Top View $(-Z)$

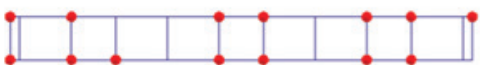

L.

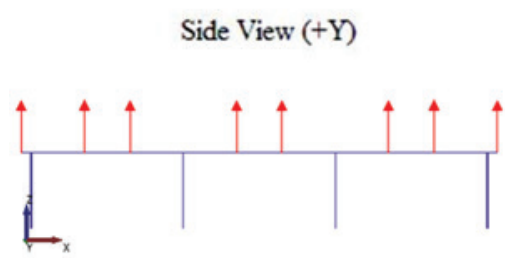

Side View $(+\mathrm{X})$

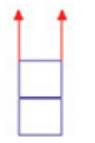

$-1$

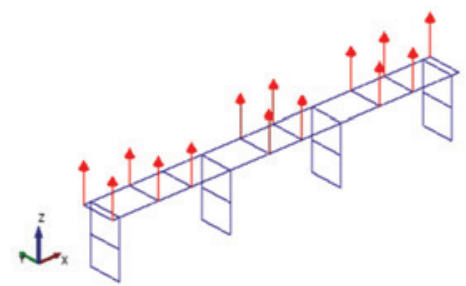

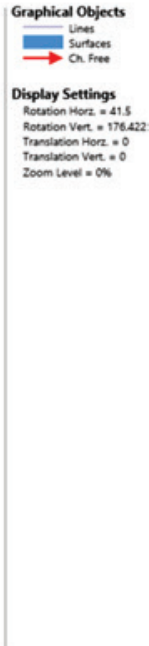

Figure 7

Overview of bridge 44 in the ARTeMIS Modal [18] 


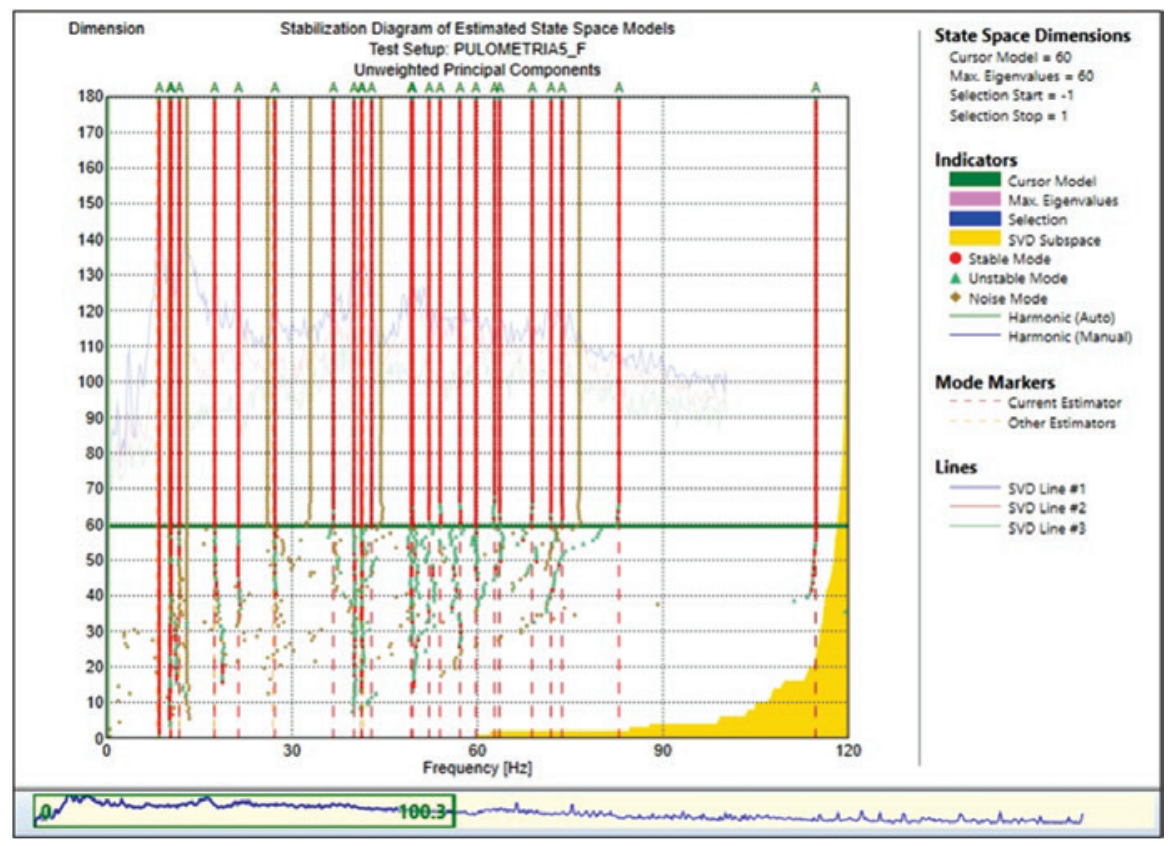

\section{Figure 8}

Stabilization diagram using 3 projection channels, 180 as model order and sampling frequency of $500 \mathrm{~Hz}$

characteristics of the software used. The standard order model used by ARTeMIS Modal [18] is 100, but this order can be changed by the user. Whether or not to use projection channels, as well as the quantity, is at the discretion of the user. However, the choice of channels is made automatically by ARTeMIS Modal [18], which first selects the channels that have the highest correlation in relation to the other channels. In case there is one more setup ${ }^{2}$, the reference accelerometers ${ }^{3}$ are taken as projection channels initially. The number of channels can be determined manually or automatically.

To visualize the influence of the projection channels in the estimation of the modal parameters, in the first analysis, the order model was considered equal to 100 and only the number of projection channels was modified (three, four, or six). In this first analysis, it was verified that the stabilization diagram that presented the least number of unstable modes was the one referring to three projection channels.

In the second analysis, the model order is varied for the different quantities of projection channels. In this way, the results were analyzed by considering model orders equal to 160 and 180 and by varying the quantities of projection channels (three, four, or six). A comparison of the obtained results showed that the analysis that considered the set with model order equal to 180 and three projection channels achieved the best results. This is because in this analysis, there was a reduction in the number of unstable modes in the stabilization diagram and in the determination of modes with lower frequencies, as shown in Figure 8 . As the frequencies estimated by the SSI-UPC method are $<100 \mathrm{~Hz}$, the spectrum was enlarged to more clearly visualize the estimated modes.

Table 1 lists the most significant natural frequencies obtained by the method. In cases where the frequencies were very close together and the mode shapes were similar, we list the ones that presented the least modal complexity.

Figures 9-12 show the well-defined mode shapes, i.e., those that can correspond to actual modes of the structure, and their respective natural frequencies.

\section{Table 1}

Frequencies and damping factors extracted from experimental modal analysis

\begin{tabular}{cccccc}
\hline $\begin{array}{c}\text { Frequency } \\
{[\mathrm{Hz}]}\end{array}$ & $\begin{array}{c}\text { Std. frequency } \\
{[\mathrm{Hz}]}\end{array}$ & $\begin{array}{c}\text { Damping } \\
{[\%]}\end{array}$ & $\begin{array}{c}\text { Std. damping } \\
{[\%]}\end{array}$ & $\begin{array}{c}\text { Complexity } \\
{[\%]}\end{array}$ & Mode type \\
\hline 8.513 & 0.003 & 0.956 & 0.069 & 0.450 & Vertical bending \\
10.290 & 0.042 & 2.626 & 0.294 & 20.535 & Vertical bending and and torsion \\
11.763 & 0.006 & 4.421 & 0.084 & 24.573 & Bending and and torsion \\
17.47 & 0.002 & 2.422 & 0.040 & 26.844 & Bending and and torsion \\
\hline
\end{tabular}

2 Setup corresponds to the positioning of the accelerometers.

${ }^{3}$ Reference accelerometers are those that repeat when there is more than one setup. 


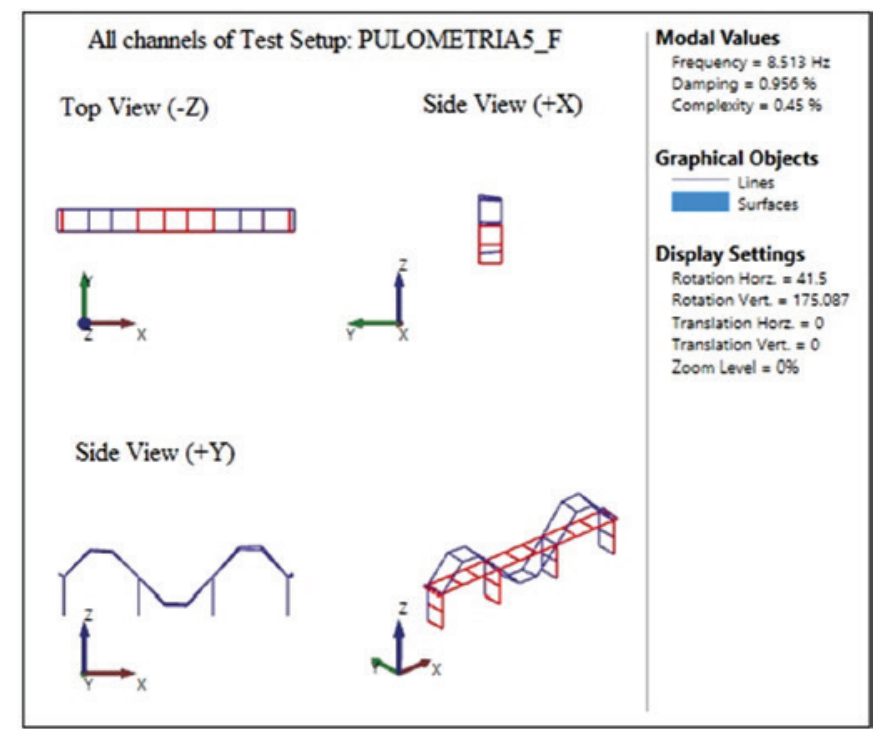

\section{Figure 9}

Vertical bending mode obtained by the SSI-UPC method in ARTeMIS Modal [18]

Figures 9-12 and Table 1 show that among the modes obtained, few represented physical modes. This could be verified from the parameter of modal complexity, which indicated that only the first mode, with a frequency of $8.513 \mathrm{~Hz}$, presented low modal complexity. The others can be considered as complex modes. Figures 13(a)-13(d) illustrate the plots of complexity for the estimated modes.

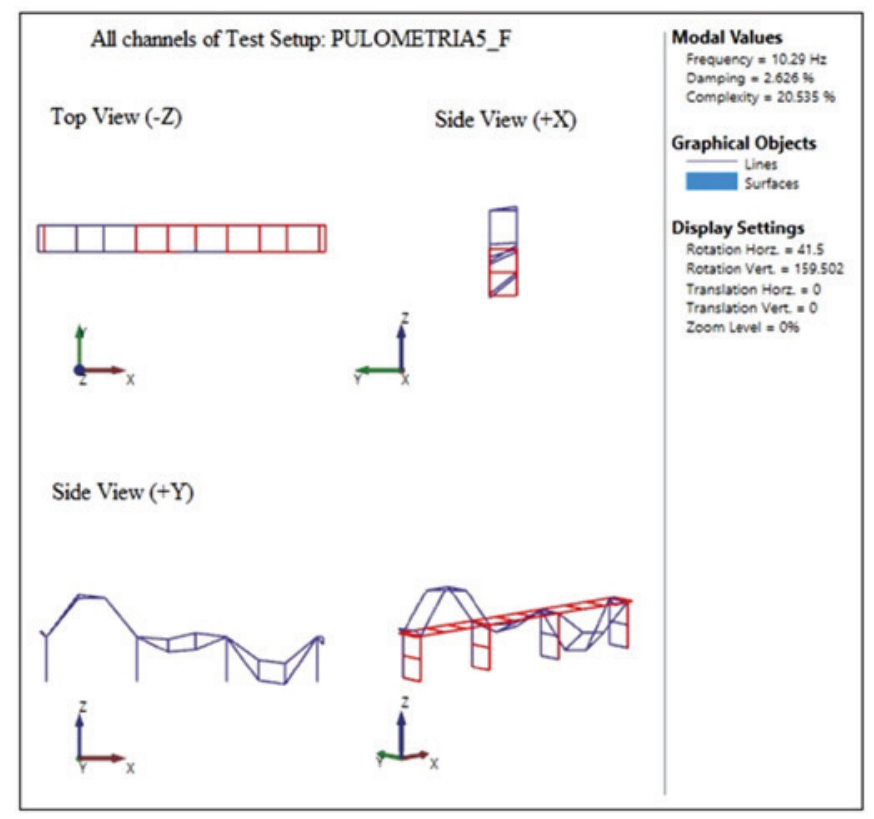

\section{Figure 10}

Vertical bending and torsion mode obtained by the SSI-UPC method in ARTeMIS Modal [18]

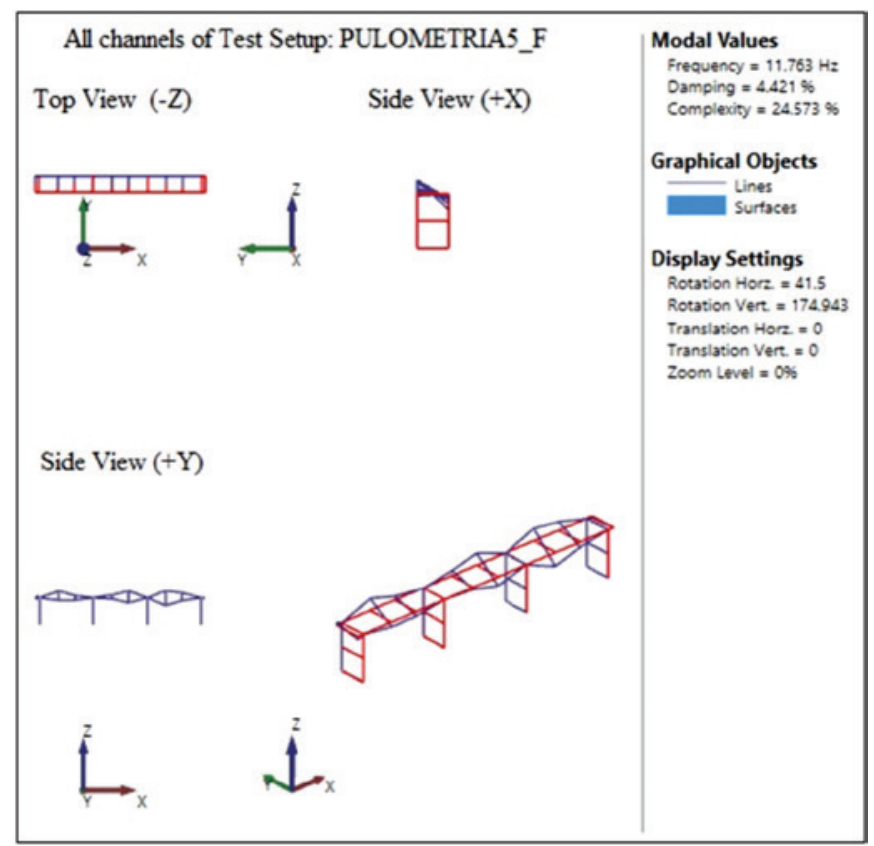

Figure 11

Vertical bending and torsion mode obtained by the SSI-UPC method in ARTeMIS Modal [18]

Despite the sophistication of the method used for identifying the modal parameters, only the first mode presented a physical mode. This may have occurred because of:

i. the limitation in the form of the excitation source applied

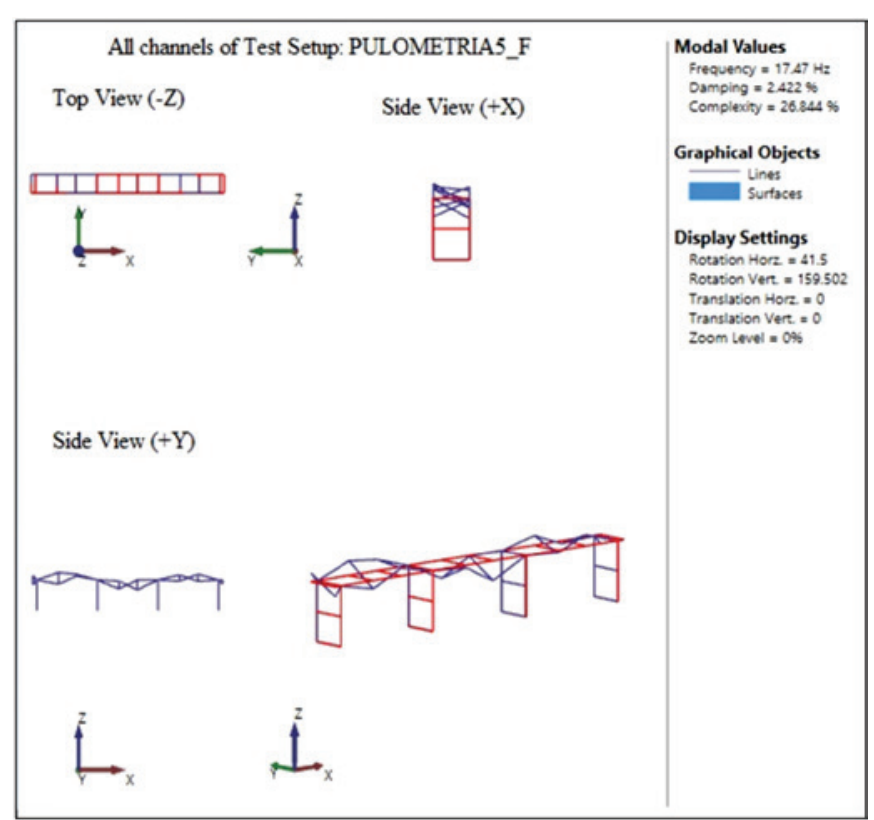

Figure 12

Vertical bending and torsion mode obtained by the SSI-UPC method in ARTeMIS Modal [18] 


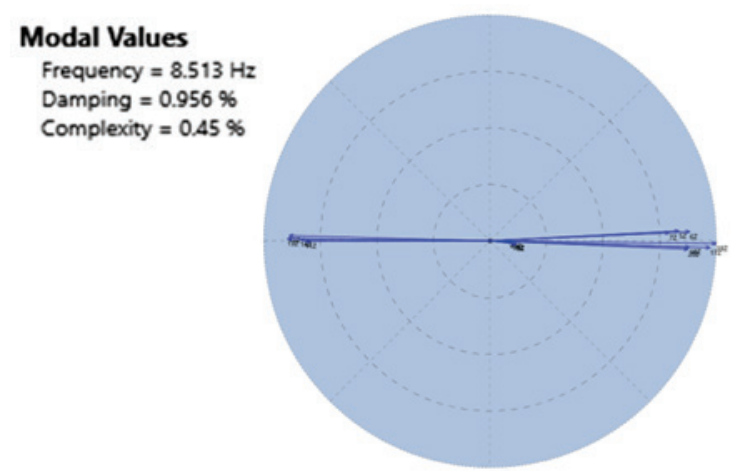

a)

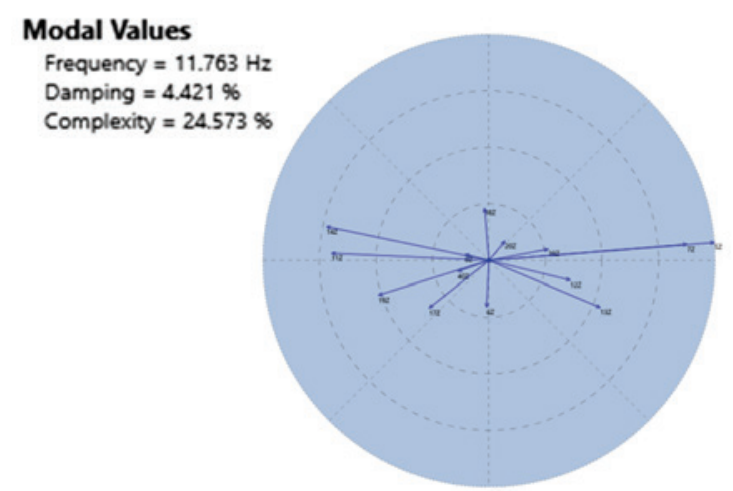

c)

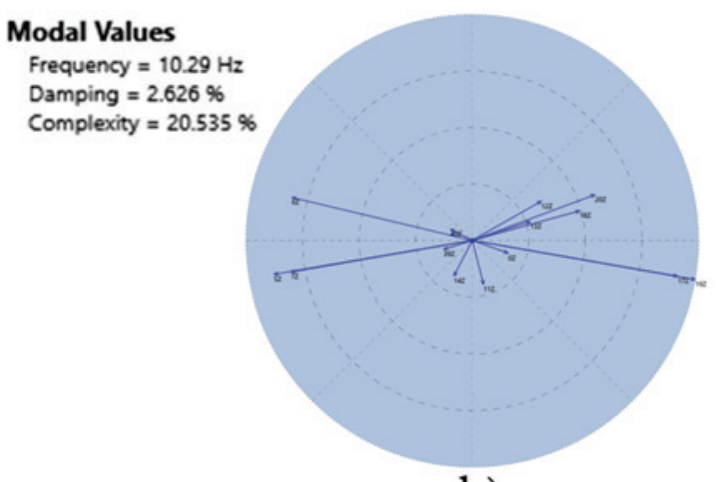

b)

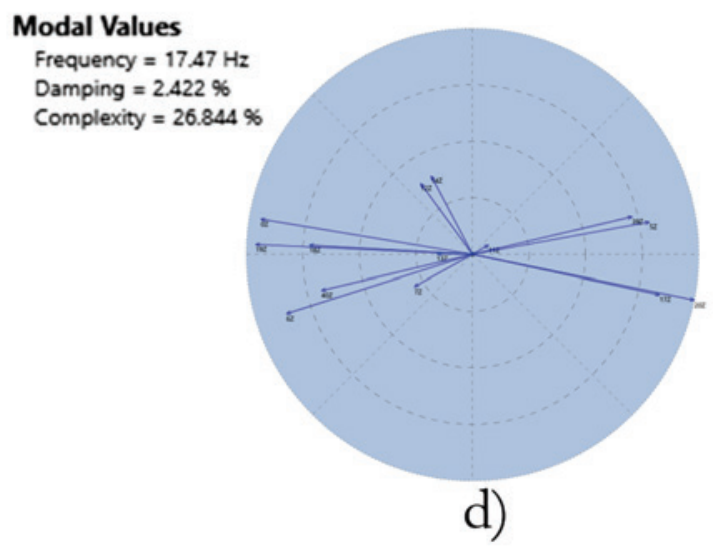

\section{Figure 13}

Modal complexity with respect to (a) mode $1 \mathrm{f}=8.513 \mathrm{~Hz}$, (b) mode $2 \mathrm{f}=10.29 \mathrm{~Hz}$, (c) mode $3 \mathrm{f}=11.763$, (d) mode $4 \mathrm{f}=17.47 \mathrm{~Hz}$

to the structure, caused by a group of people jumping on each span of a continuous beam (not concomitantly);

ii. the energy contained in the excitation source; and

iii. an insufficient number of measurement points because some vertical accelerometers did not work and had to be discarded from the analysis.

\section{Finite element models}

For characterizing the dynamic behavior of a structure, it is necessary to have an adequate idealization of the actuating actions, knowledge of the geometric and mechanical properties of the constituent structural elements, and a numerical model that can obtain, in a rigorous manner, the main characteristics of the structural response according to the characteristics of the excitation. The definition of the numerical model depends on the stiffness and mass of the simulated structure. A numerical model was developed in CSiBridge [16] to determine the natural frequencies and their modal shapes.

In the numerical model, the superstructure, the mesostructure, and part of the infrastructure (drilled pier) were represented by frame elements. The foundation blocks were modeled as shell elements. Because the columns and the su-

\section{Table 2}

Values of the stiffnesses of bearings pads of the extremities and the columns

\begin{tabular}{ccc}
\hline \multicolumn{3}{c}{ Stiffnesses of the extremities } \\
\hline \multicolumn{1}{c}{ Direction } & Stiffness & Units \\
\hline Axial $(y$ direction) & 3413837.56 & $(\mathrm{kN} / \mathrm{m})$ \\
Shear in $x$ & 2949.66 & $(\mathrm{kN} / \mathrm{m})$ \\
Shear in $z$ & 2949.66 & $(\mathrm{kN} / \mathrm{m})$ \\
Rotation around $y$ & 0.00 & $(\mathrm{kN} . \mathrm{m} / \mathrm{rad})$ \\
Rotation around $x$ & 0.00 & $(\mathrm{kN} . \mathrm{m} / \mathrm{rad})$ \\
Rotation around $z$ & 9290.35 & $(\mathrm{kN} . \mathrm{m} / \mathrm{rad})$ \\
\hline
\end{tabular}

\begin{tabular}{|c|c|c|}
\hline \multicolumn{3}{|c|}{ Stiffness of the columns bearing pads } \\
\hline Direction & Stiffness & Units \\
\hline Axial (y direction) & 20264475.64 & $(\mathrm{kN} / \mathrm{m})$ \\
\hline Shear in $\mathrm{x}$ & 7163.45 & $(\mathrm{kN} / \mathrm{m})$ \\
\hline Shear in z & 7163.45 & $(\mathrm{kN} / \mathrm{m})$ \\
\hline Rotation around y & 0.00 & $(\mathrm{kN} \cdot \mathrm{m} / \mathrm{rad})$ \\
\hline Rotation around $\mathrm{x}$ & 0.00 & $(\mathrm{kN} \cdot \mathrm{m} / \mathrm{rad})$ \\
\hline Rotation around z & 137020.54 & $(\mathrm{kN} \cdot \mathrm{m} / \mathrm{rad})$ \\
\hline
\end{tabular}


Table 3

Values of the soil rigidities

(Rodrigues Junior et al. [14])

\begin{tabular}{|c|c|c|}
\hline \multicolumn{3}{|c|}{ Block 1} \\
\hline$z(m)$ & $\mathrm{Kh}(\mathrm{kN} / \mathrm{m})$ & $\mathrm{Kv}(\mathrm{kN} / \mathrm{m})$ \\
\hline 0.00 & 10452 & 14419 \\
\hline 19.00 & 211127 & 339083 \\
\hline Shear in z & 2949.66 & $(\mathrm{kN} / \mathrm{m})$ \\
\hline \multicolumn{3}{|c|}{ Block 2 (Column 1) } \\
\hline$z(m)$ & $\mathrm{Kh}(\mathrm{kN} / \mathrm{m})$ & $\mathrm{Kv}(\mathrm{kN} / \mathrm{m})$ \\
\hline 0.00 & 13947 & 20983 \\
\hline 10.00 & 275867 & 555676 \\
\hline Shear in $z$ & 2949.66 & $(\mathrm{kN} / \mathrm{m})$ \\
\hline \multicolumn{3}{|c|}{ Block 3 (Column 2) } \\
\hline$z(m)$ & $\mathrm{Kh}(\mathrm{kN} / \mathrm{m})$ & $\mathrm{Kv}(\mathrm{kN} / \mathrm{m})$ \\
\hline 0.00 & 13947 & 20983 \\
\hline 10.00 & 275867 & 555676 \\
\hline Shear in z & 2949.66 & $(\mathrm{kN} / \mathrm{m})$ \\
\hline \multicolumn{3}{|c|}{ Block 4} \\
\hline$z(m)$ & $\mathrm{Kh}(\mathrm{kN} / \mathrm{m})$ & $\mathrm{Kv}(\mathrm{kN} / \mathrm{m})$ \\
\hline 0.00 & 10452 & 14419 \\
\hline 19.00 & 211127 & 339083 \\
\hline Shear in z & 2949.66 & $(\mathrm{kN} / \mathrm{m})$ \\
\hline
\end{tabular}

perstructure were modeled in this manner, it was necessary to use rigid elements (links) to connect different elements (stringers with columns, columns with foundation blocks, and foundation blocks with the drilled pier) to preserve the correct geometry of the structure.

Spring elements were placed on the top of the columns to simulate the bearing pads and in the infrastructure elements (blocks and the top and base of the drilled piers) to represent the vertical and horizontal soil stiffnesses. The drilled piers were considered to be fixed. The values of the stiffnesses and the rotations of the bearing pads are given in Table 2. These were calculated according to empirical expressions presented in Pfeil [19].

\section{Table 4}

Values of the elastic modulus of concrete (Rodrigues Junior et al. [14])

\begin{tabular}{cc}
\hline Element & $\begin{array}{c}\text { Elastic modulus } \\
(\mathrm{GPa})\end{array}$ \\
\hline Abutment E1 CPO1 & 31.986 \\
Abutment E1 CPO2 & 28.948 \\
Column P1 CPO1 & 35.071 \\
Column P1 CPO2 & 34.113 \\
Block B2 CPO1 & 33.234 \\
Block B2 CPO2 & 30.250 \\
Stringer CPO1 & 36.551 \\
Stringer CPO2 & 37.576 \\
Average superstructure & 35.828 \\
Average Infrastructure & 31.1045 \\
\hline
\end{tabular}

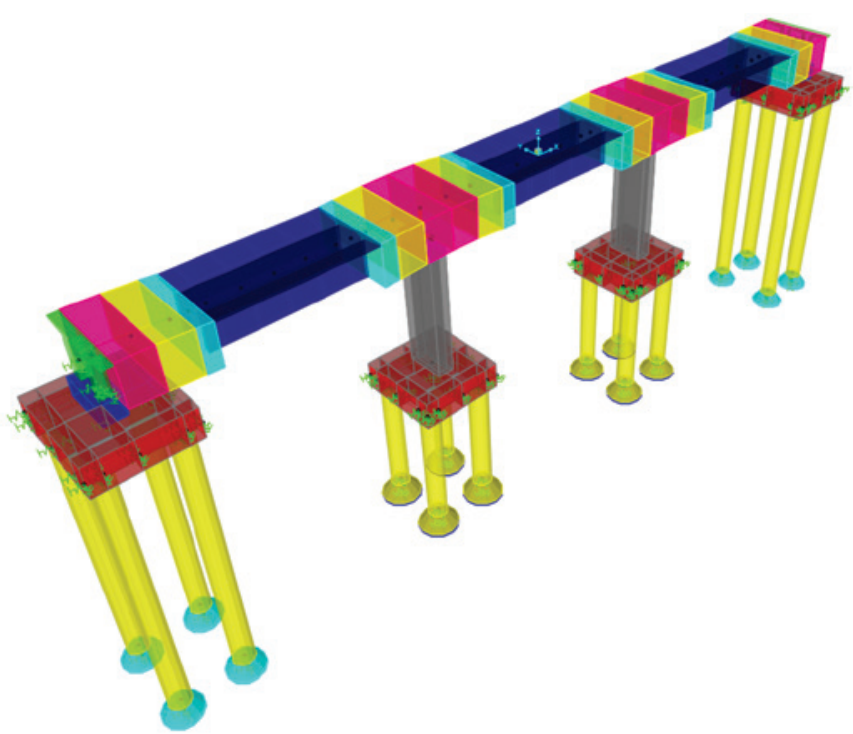

\section{Figure 14}

Variation of the sections of the elements of the structure, modeled in the CSiBridge software [16]

Soil rigidities were obtained from a standard penetration test and are listed in Table 3 . These were simulated by placing springs on the top and base of the drilled piers, on the foundation blocks, and on the other elements that were in contact with the soil.

The superstructure was modeled as a $\Pi$-shaped section, in agreement with the original project. The bases of the stringers ranged from 35 to $70 \mathrm{~cm}$ in the longitudinal axis direction. To represent this variation, the variable stretch of the stringers was discretized into three parts: $70-57 \mathrm{~cm}, 57-41 \mathrm{~cm}$, and $41-35 \mathrm{~cm}$, as shown in Figure 14. The stretches with a constant section $(35 \mathrm{~cm})$ were discretized into six elements to provide a more precise analysis, and the bridge deck was discretized into 38 elements.

The elastic modulus of the concrete was calculated from the average of the elastic moduli obtained via experimental tests conducted by Rodrigues Júnior et al. [14], as presented in Table 4 .

For the modeled elements (drilled piers, foundation blocks, columns, stringers, and slabs), a specific weight of $25 \mathrm{kN} /$ $\mathrm{m}^{3}$ was used, referring to reinforced concrete. The additional mass on the deck (ballast, sleepers, rails, etc.) and transversal girders were modeled as distributed masses or concentrated along the structure, respectively. Table 5 summarizes the load and mass values used in the model.

After the structure was modeled in CSiBridge [16], it was possible to visualize the modes identified numerically and their respective natural frequencies. Table 6 lists these results with their respective modal participation factors (effective mass ratio). According to Macaia [6], the participation factor allows one to evaluate the relevance of a certain mode of vibration in the response of a structure when subjected to an excitation. As can be seen in Table 6 , modes 6 and 8 , shown in 


\section{Table 5}

Loads used in the numerical model

\begin{tabular}{ccc}
\hline Element & Weight & Mass \\
\hline Ballast, sleepers, rails and accessories & $60.98 \mathrm{kN} / \mathrm{m}$ & $6218.00 \mathrm{~kg} / \mathrm{m}$ \\
Intermediate transversal beams $(2.80 \mathrm{~m} \times 1.75 \mathrm{~m} \times 0.30 \mathrm{~m})$ & $36.75 \mathrm{kN}$ & $3747.32 \mathrm{~kg}$ \\
Central support transversal beams $(2.80 \mathrm{~m} \times 2.45 \mathrm{~m} \times 0.70 \mathrm{~m})$ & $120.05 \mathrm{kN}$ & $12241.25 \mathrm{~kg}$ \\
Transversal beams of the extreme supports $(2.80 \mathrm{~m} \times 2.45 \mathrm{~m} \times 0.50 \mathrm{~m})$ & $85.75 \mathrm{kN}$ & $8743.75 \mathrm{~kg}$ \\
Refuge. including refuge railing & $11.50 \mathrm{kN}$ & $1172.63 \mathrm{~kg}$ \\
\hline
\end{tabular}

Table 6

Factors of modal mass participation

\begin{tabular}{cccccccc}
\hline Mode & $\begin{array}{c}\text { Frequency } \\
{[\mathrm{Hz}]}\end{array}$ & UX & UY & UZ & $\Sigma$ UX & $\Sigma$ UY & $\Sigma$ UZ \\
\hline 1 & 1.054 & $2.32 \mathrm{E}-10$ & 0.99431 & $7.959 \mathrm{E}-15$ & $2.322 \mathrm{E}-10$ & 0.99431 & $7.959 \mathrm{E}-15$ \\
2 & 1.064 & $1.00 \mathrm{E}+00$ & $2.316 \mathrm{E}-10$ & $5.784 \mathrm{E}-11$ & 1 & 0.99431 & $5.785 \mathrm{E}-11$ \\
3 & 1.446 & $1.16 \mathrm{E}-13$ & $5.305 \mathrm{E}-10$ & $1.512 \mathrm{E}-13$ & 1 & 0.99431 & $5.8 \mathrm{E}-11$ \\
4 & 3.624 & $8.46 \mathrm{E}-14$ & 0.00567 & $1.6 \mathrm{E}-12$ & 1 & 0.99998 & $5.96 \mathrm{E}-11$ \\
5 & 8.407 & $6.79 \mathrm{E}-16$ & $1.234 \mathrm{E}-13$ & $5.457 \mathrm{E}-10$ & 1 & 0.99998 & $6.053 \mathrm{E}-10$ \\
6 & 8.604 & $1.92 \mathrm{E}-10$ & $1.007 \mathrm{E}-16$ & 0.11114 & 1 & 0.99998 & 0.1114 \\
7 & 9.865 & $2.17 \mathrm{E}-07$ & $8.792 \mathrm{E}-18$ & $1.295 \mathrm{E}-11$ & 1 & 0.99998 & 0.1114 \\
8 & 12.181 & $1.78 \mathrm{E}-11$ & $8.71 \mathrm{E}-17$ & 0.76201 & 1 & 0.99998 & 0.87341 \\
\hline
\end{tabular}

Figure 15, exhibited the highest modal participation factors (highest effective mass ratio values). It is noted that mode 8 , whose frequency was $12.18 \mathrm{~Hz}$, exhibited the highest modal participation factor, $\sim 76 \%$. Therefore, it was expected that this mode would correspond to the first mode identified experimentally; however, this was not the case, because mode 6 exhibited a modal shape and natural frequency closest to the experimentally identified ones, as can be seen in Figure 16.

Experimentally identifying the eighth numerical mode requires the imposition of displacements on the three spans with sufficient energy to induce vibration and with sufficiently high amplitude (signal/noise ratio). This was not possible owing to the limitation in the manner in which the excitation source was applied during the testing phase (i.e., a group of people jumping on each continuous beam section, in a nonconcomi- tant manner). The excitation energy provided by the mass of the group of people jumping was low when compared with the high mass required to induce vibration in the section.

\section{Conclusions}

The main objective of this study was to obtain the modal parameters of bridge 44 of the Carajás Railroad, located over the Martírio River, through experimental data obtained during in situ monitoring. The results were then compared with the results obtained through a numerical model developed in CSiBridge software [16].

In this case study, vibration produced by a group of people jumping on each span of the bridge was monitored. The sampling frequency used during data acquisition was $500 \mathrm{~Hz}$.

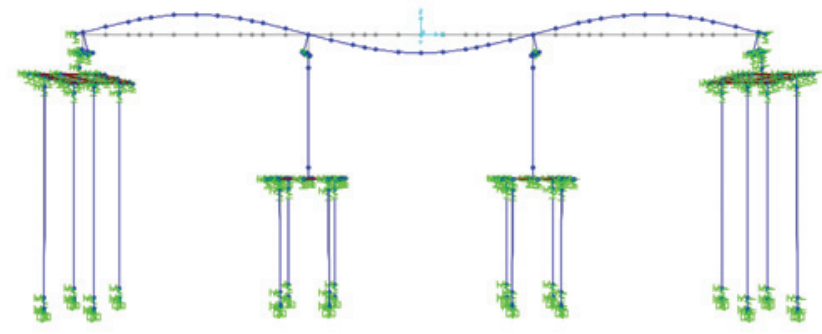

(A)

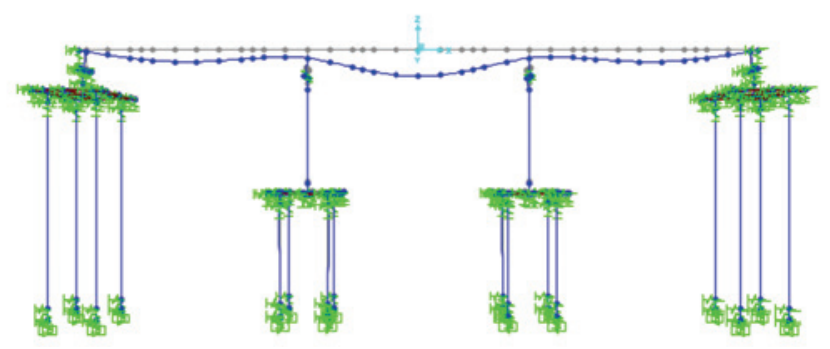

(B)

Figure 15

(a) Sixth mode identified from the numerical model, developed in CSiBridge [16],

(b) Eighth mode identified from the numerical model, developed in CSiBridge [16] 


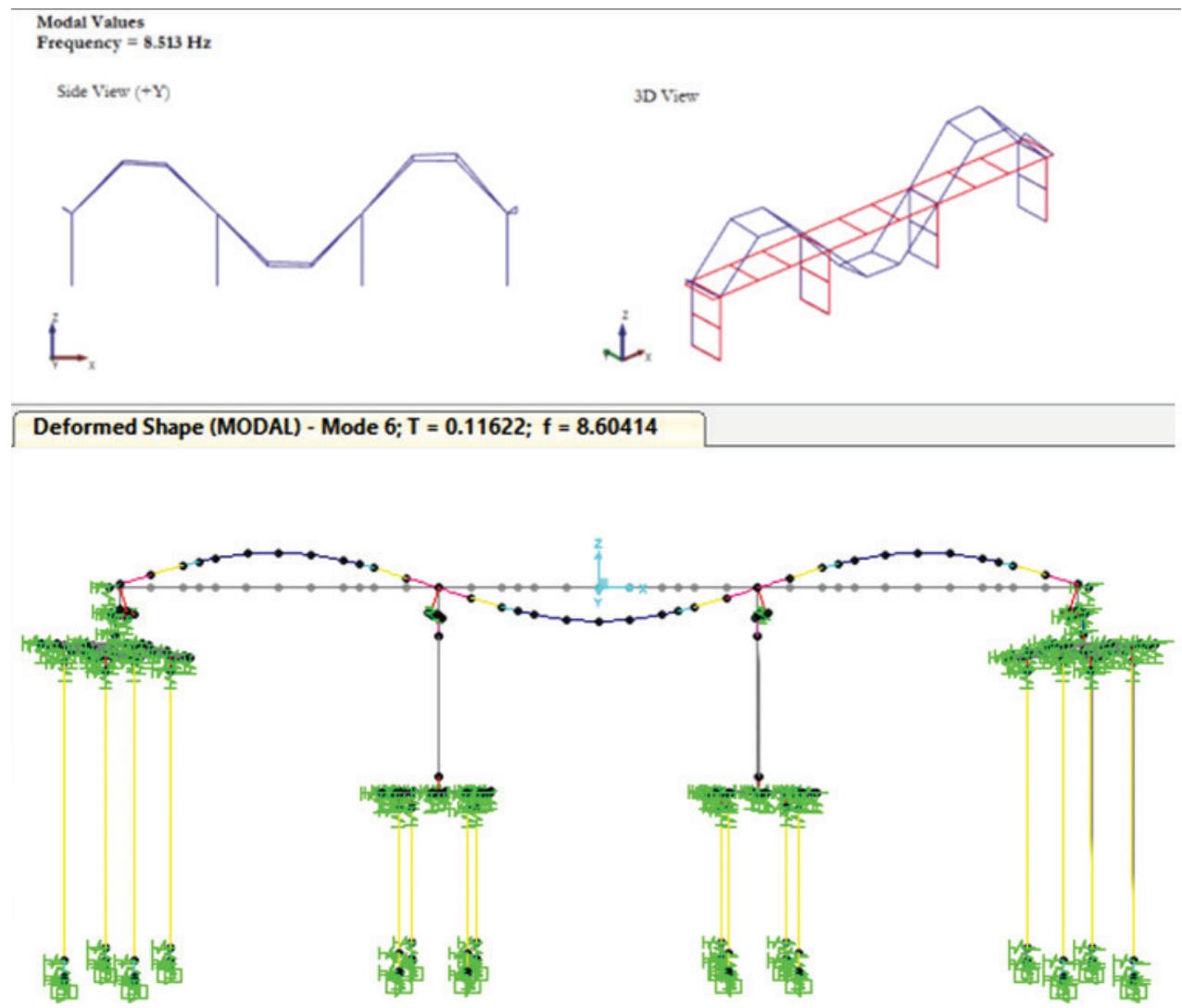

\section{Figure 16}

Comparison between the first mode obtained via the SSI-UPC method with the first mode obtained via the numerical model

For the estimation of modal parameters, ARTeMIS Modal software [18] was used. Two tests were performed: In the first one, only the accelerometers that did not capture a signal were removed; in the second, the transverse accelerometers as well as the ones that did not capture a signal were discarded. In the first test, the results obtained were not satisfactory, because there were more unstable modes than stable ones. Therefore, we presented only the results obtained from the second test. For the SSI-UPC method, analyses were performed by varying the number of projection channels and the model order. It was observed that using three projection channels and 180 as the model order reduced the number of unstable modes in the stabilization diagram and the appearance of modes with lower frequencies. Consequently, only those results were presented. Despite the sophistication of the method used to obtain the modal parameters experimentally, only the first mode of vertical flexion was identified and validated with the numerical model. This may be justified by the manner in which the structure was excited and by the limited energy provided by a group of people jumping. To experimentally identify mode 8 , the application of a simultaneous excitation to the three spans of the bridge will be required, which was not possible during the monitoring phase owing to the limited number of people, who could not produce sufficient excitation energy.
To identifying the frequency of mode 6 , which corresponds to the first experimental vertical bending mode, only one of the spans requires excitation. This can be explained based on the theory of vibration of continuous girders, which establishes that a continuous girder with $n$ spans of length $L$ will have the same first vibration frequency (fundamental frequency) of a simply supported beam L [20].

\section{Acknowledgments}

To the teachers and students of the Nucleus of Instrumentation and Computation Applied to Engineering (NICAE), an associate group of UFPA, who kindly gave us the data used in the research.

To the Coordination of Improvement of Higher-Level Personnel - CAPES, to the Gorceix Foundation, to Fapemig and to the Graduate Program in Civil Engineering - PROPEC, for the financial support.

\section{References}

[1] FARRAR, C., R. WORDEN, K. Structural health monitoring: a machine learning perspective. Chichester: John Wiley \& Sons, 2013. 
LOBATO, A. L.S., NETO, R. P. J., AMADOR, R. D. S. SOUZA, M. R., SAMPAIO, C. A. R. Modal analysis experimental and computational of a railway bridge metallic. Metal Building Magazine - Edition $n^{\circ} 92-$ ABCEM.

[3] SAMPAIO, C. A. R., CHAN, T. H. T. Modal parameters identification of heavy-haul railway RC bridges - experience acquired. Structural Monitoring and Maintenance, Vol. 2, No. 1 (2015) 1-18. COSTA, C., RIBEIRO, D., JORGE, P., SILVA, R., ARÊDE, A., CALÇADA, R. Calibration of the numerical model of a stone masonry railway bridge based on experimentally identified modal parameters. Portugal: Elsevier, 2016. p.354-371.

[6] MACAIA, E. D. Experimental identification of the modal properties of a structure. Masters dissertation. Faculty of Science and Technology. New University of Lisbon, 2017.

[5] SULEYMAN, E. N. Dynamic monitoring of the São João railway bridge. Lisboa, 2016, Masters dissertation. - Higher Institute of Engineering of Lisbon. RODRIGUES, J. Stochastic modal identification Analysis methods and applications in civil engineering structures. Thesis. FEUP, 2004.

[7] VAN OVERSCHEE, P., DE MOOR, B. Subspace Identification for Linear Systems: Theory, implementation, applications.Kluwer Academic Publishers, 1996.

[8] PEETERS B. System Identification and Damage Detection in Civil Engineering. PhD Thesis, Department of Civil Engineering, K. U. Leuven, Belgium, 2000.

[9] WENG, J.H., LOH, C.H., LYNCH, J.P., LU, K.C., LIN, P.Y., WANG, Y. Output-only modal identification of a cable-stayed bridge using wireless monitoring systems. Engineering Structures, v. 30, 2008, p. 1820-1830.

[10] ANDERSEN, P. K., BRINCKER, R. Filtering out environmental effects in damage detection of civil engineering structures, IMAC XV, Kissimmee, USA, 1997.

[11] LJUNG, L. System Identification - Theory for the User, 2nd edition, Prentice Hall, USA, 1999.

[12] HERLUFSEN, H., GADE, S., MØLLER, N. dentification techniques for operational modal analysis - an overview and practical experiences, Proceedings of the IMAC-XXIV: Conference on Structural Dynamics, St Louis, Missouri, USA. January. 2006.

[13] NGUYEN, T., CHAN, T., THAMBIRATNAM, D. Effects of wireless sensor network uncertainties on outputonly modal analysis employing merged data of multiple tests. Advances in Structural Engineering, 17(3), 2015, p. $319-330$.

[14] RODRIGUES JÚNIOR, J. S., CARNEIRO, M. F. J. R., SAMPAIO, C. A. R., DALTRO, M. A. SILVA, S. M., LEAL, C. A. M., MORAES, E., QUEIROZ, B. F. A. Final Report - Bridge n. 44 over the Martírio River. Belém, Pará, 2012.

[15] ABNT NBR 15307:2006 - Non-destructive tests - Proof of dynamic loads in large structures - Procedure.
[16] CSIBRIDGE, Copyright Computers and Structures, CSiBridge, Inc. 2014, Version 17.0.0, 2015.

[17a] AqDados 7, Lynx Tecnologia Eletrônica Ltda, Version 7.0.2.1, 2011.

[17b] AqDanalysis 7, Lynx Tecnologia Eletrônica Ltda, Version 7.0.2.1, 2011.

[18] ARTEMIS MODAL, Structure Vibration and Solutions A/S, Version 3.5.0.0, 2014.

[19] PFEIL, W. Pontes em Concreto Armado. Vol. 2. LTC Editora. 1997. Rio de Janeiro. Brazil (in Portuguese).

[20] HAYASHIKAWA, T., WATANABE, N. Free vibration analysis of continuous beams. J. Eng. Mech., 1985. 